(Civil Engineeering, Elektrical Engineeering and Industrial Engineeering)

Vol. 16, No. 2, Oktober 2019, p-ISSN:1907-5243, e-ISSN: 2655-8416

\title{
BAHAN BAKAR CAIR DARI LIMBAH PLASTIK DENGAN METODE CATALYTIC CRACKING
}

\author{
Renilaili \\ Dosen Universitas Bina Darma \\ Jalan Jenderal Ahmad Yani No.12, Palembang \\ Pos-el: renilaili@binadarma.ac.id
}

\begin{abstract}
Indonesia with a very large population, is currently working hard to diversify its energy, in order to meet energy needs in the country, especially electricity and fuel energy, preferably environmentally friendly renewable energy, when this plastic waste becomes national problems because they cannot decompose under ordinary conditions unless they are converted into chemical fuel. This study aims to obtain liquid fuel energy, in this case used HDPE plastic waste raw material (in the form of packaged drinking water), this plastic waste is processed using the Catalitic Cracking method with silica Alumina as a catalyst, the process lasts for 4 hours with a temperature of $100-400 \circ \mathrm{C}$ and $53 \%$ of the plastic oil obtained, brownish yellow, with density and viscosity and flash point approaching kerosine compounds to diesel fuel, in the process of catalytic cracking, temperature factors, process length and the catalyst used greatly affect the number of products and product quality from the liquid fuel produced.
\end{abstract}

Keywords: Plastic waste, Catalytic Cracking, catalyst, liquid fuel

\section{PENDAHULUAN}

\subsection{Latar belakang}

Seiring bertambahnya penduduk Indonesia, maka bertambah pula kebutuhan akan segala aktifitas yang dibutuhkan baik dibidang energy , kebutuhan makanan, kebutuhan akan kesehatan, sampai kebutuhan pakaian, serta kemasan. Kebutuhan akan energy ini sangat besar sekali karena Indonesia merupakan Negara besar dengan jumlah penduduk berkisar antara 200- 270 juta orang. Penduduk yang besar ini sangat lah membutuhkan sandang pangan yang besar serta energy yang besar pula, Energi terutama energy bahan bakar yang berasal dari fosil , makin lama semakin menipis, oleh karena itu diperlukan usaha untuk Diversifikasi energy yang berguna untuk mencukupi akan kebutuhan terutama untuk bahan bakar, energy listrik serta energy lain yang sangat dibutuhkan.Dalam usaha untuk diversifikasi akan listrik saat ini Pemerintah lebih mengutamakan energy yang ramah lingkungan seperti energy 
(Civil Engineeering, Elektrical Engineeering and Industrial Engineeering)

Vol. 16, No. 2, Oktober 2019, p-ISSN:1907-5243, e-ISSN: 2655-8416

surya, energy angin, energy mikro hidro dan sebagainya. Dalam hal energy yang berfungsi sebagai bahan bakar, Pemerintah juga saat ini lebih mengutamakan energy yang ramah lingkungan seperti energy biogas, energy bioethanol dan lain lain yang bersifat ramah lingkungan.

Pemerintah Indonesia saat ini sedang giat giatnya untuk melakukan diversifikasi energy terutama untuk mencukupi akan kebutuhan dalam negeri, energy listrik dan energy terbarukan yang bisa berfungsi sama dengan energy listrik . Energi surya sangat digalakkan terutama untuk daerah pedesaan yang jauh terpencil, disamping itu energy biogas untuk perkotaan dan juga pedesaan yang bisa dilakukan untuk menggantikan energy bahan bakar.

Saat ini yang sangat menjadi permasalahan yang serius adalah masalah sampah plastik, yang mana sampah ini tidak bisa diuraikan oleh seperti kompos yang kembali menjadi hancur dan menjadi tanah, karena plastic tidak bisa diuraikan dengan cara biasa, maka perlu dilakukan cara lain yaitu secara kimia. Sampah plastic ini mempunyai kelebihan dan kekurangan, kelebihan bahan plastic ini adalah kuat, ringan, fleksibel, tahan karat dan tidak mudah pecah, mudah diberi warna, dan mudah dibentuk, serta isolator panas dan listrik yang baik. Disamping kelebihan diatas ada kekurangannya karena plastic tidak bisa terurai secara alamiah melainkan harus diolah dengan temperature tinggi, agar bisa terurai secara kimia [1]

Tujuan dalam penelitian ini adalah untuk mendapatkan bahan bakar cair yang berasal dari limbah plastic diutamakan dari jenis poly ethylene baik yang berasal dari high density poli ethylene maupun dari Low density poli ethylene.

Untuk mengurangi banyak nya limbah plastic yang saat ini menjadi masalah maka ada 3 meode yang bisa digunakan untuk mengubah limbah plastic menjadi bahan bakar cair, ke 3 metode tersebut adalah Meode Thermal Cracking , metode Hydro Cracking dan Metode Catalytic Cracking. Selain metode proses, jenis katalis juga sangat mempengaruhi tinggi rendahnya komposisi produk yang dihasilkan, dengan dikembangkan nya metode tersebut limbah plastic yang selama ini menjadi permasahan serius di masyarakat, dapat menjadi sesuatu yang bermanfa'at bagi lingkungan dan masyarakat.

\subsection{Jenis-jenis Plastik}

Plastik adalah salah satu jenis makromolekul, yang dibentuk dengan proses polimerisasi. 
(Civil Engineeering, Elektrical Engineeering and Industrial Engineeering)

Vol. 16, No. 2, Oktober 2019, p-ISSN:1907-5243, e-ISSN: 2655-8416

Polimerisasi adalah proses penggabungan beberapa molekul sederhana (monomer) melalui proses kimia menjadi molekul besar ( makro molekul atau polimer ),plastic adalah senyawa polimer yang unsur penyusun utamanya adalah Karbon dan Hidrogen [1].

Plastik disekitar kita secara komersil terdiri dari beberapa jenis plastic, diantara nya Poly ethylene (PE), Poly Vinyl chloride (PVC), Poly propylene (PP), Poly Methyl Metaacrylate (PMMA) , Acronitril Butadiene Styrene (ABS) serta Polyester Trepthalat (PET). Distribusi plastic yang terdapat dimasyarakat banyak berasal dari Poly ethylene, sedangkan senyawa dari

poly ethylene sendiri terdiri dari 2 bagian yaitu hygh density poly ethylene yang banyak di gunakan untuk membuat botol minuman kemasan, sedang low density poly ethylene banyak digunakan untuk membuat kantong plastic [2].

\subsection{Poly Ethylene}

Poly ethylene terdiri dari dua macam yaitu, HDPE dan LDPE, Low Density Polyethylene (LDPE), sifat mekanis jenis plastik ini adalah kuat, agak tembus cahaya, fleksibel dan permukaan agak berlemak. Pada suhu dibawah $60^{\circ} \mathrm{C}$ sangat resisten terhadap senyawa kimia, daya proteksi terhadap uap air tergolong baik, akan tetapi kurang baik bagi gas-gas yang lain seperti oksigen.

High Density Polyethylen (HDPE), jenis plastik ini lebih kaku, lebih keras, kurang tembus cahaya dan kurang terasa berlemak. Pada HDPE jumlah molekul rantai cabang lebih sedikit, dengan demikian high density memiliki sifat bahan yang lebih kuat, keras, buram, dan lebih tahan terhadap suhu tinggi. Ikatan hidrogen antar molekul juga berperan dalam , menentukan titik leleh plastik.

\subsection{Sifat Thermal Bahan Plastik}

Pengetahuan sifat thermal dari berbagai jenis plastik sangat penting dalam proses pembuatan dan daur ulang plastik.Sifat-sifat thermal yang penting adalah temperatur lebur ( $\mathrm{Tm})$, temperatur transisi ( $\mathrm{Tg}$ ) dan Temperatur dekomposisi.Temperatur transisi adalah temperatur dimana plastik mengalami perenggangan struktur, sehingga terjadi perubahan dari kondisi kaku menjadi fleksibel. Diatas titik lebur, plastik mengalami pembesaran volume, sehingga molekul bergerak lebih bebas yang ditandai dengan peningkatan kelenturan nya.Temperatur Lebur adalah temperatur dimana plastik mulai melunak dan berubah menjadi cair. Temperatur Dekomposisi merupakan batasan dari proses 
(Civil Engineeering, Elektrical Engineeering and Industrial Engineeering)

Vol. 16, No. 2, Oktober 2019, p-ISSN:1907-5243, e-ISSN: 2655-8416

pencairan, jika suhu dinaikkan diatas temperatur lebur, plastik akan mudah mengalir dan struktur akan mengalami dekomposisi. Dekomposisi terjadi karena energi thermal melampaui energi yang mengikat rantai molekul.Secara umum polimer akan mengalami dekomposisi pada suhu diatas 1,5 kali dari temperatur transisinya [3]

Tabel 1. Data Tempratur Transisi dan Tempratur lebur plastik

\begin{tabular}{lccc}
\hline Jenis bahan & $\operatorname{Tm}\left({ }^{\circ} \mathrm{C}\right)$ & $\operatorname{Tg}\left({ }^{\circ} \mathrm{C}\right)$ & $\begin{array}{c}\text { Temperatur kerja } \\
\text { maks }\left({ }^{\circ} \mathrm{C}\right)\end{array}$ \\
\hline PP & 168 & 5 & 80 \\
HDPE & 134 & -110 & 82 \\
LDPE & 330 & -115 & 260 \\
PA & 260 & 50 & 100 \\
PET & 250 & 70 & 100 \\
ABS & & 110 & 85 \\
PS & & 90 & 70 \\
PMMA & & 100 & 85 \\
PC & & 150 & 246 \\
PVC & & 90 & 71 \\
\hline
\end{tabular}

Sumber : Budiyantoro,2010

Data sifat thermal yang penting pada proses daur ulang plastik bisa dilihat pada tabel diatas. Daur ulang (Recycle) sampah plastik dapat dibedakan menjadi 4 cara, yaitu daur ulang primer adalah daur ulang limbah plastik yang memiliki kualitas yang hampir setara dengan produk aslinya, daur ulang sekunder adalah daur ulang yang menghasilkan produk yang sejenis tapi mempunyai kualitas dibawahnya, sedang daur ulang tersier adalah daur ulang sampah plastik menjadi bahan bakar, dan yang teakhir adalah daur ulang quarter, adalah proses untuk mendapatkan energi (Nilai kalor) yang terkandung didalam sampah plastik [4].

\section{METODOLOGI PENELITIAN}

Dalam Penelitian ini digunakan metode Cataytic Cracking dengan menggunakan katalis Silica Alumina. Proses perengkahan (Cracking) yaitu reaksi 
(Civil Engineeering, Elektrical Engineeering and Industrial Engineeering)

Vol. 16, No. 2, Oktober 2019, p-ISSN:1907-5243, e-ISSN: 2655-8416

pemutusan ikatan C-C dari rantai karbon panjang dan berat molekul besar menjadi rantai karbon pendek dan berat molekul kecil, dengan menggunakan temperatur yang cukup tinggi serta katalis yang digunakan, dengan perpindahan kalor secara konduksi, konveksi dan radiasi [5]. Pada temperatur $100^{\circ} \mathrm{C}$, plastik akan mulai meleleh dan menguap sampai $400^{\circ} \mathrm{C}$, eksperimen dilakukan dalam laboratotrium proses produksi dengan menggunakan peralatan sebagai berikut.

\section{Bahan dan Alat yang digunakan adalah sbb:}

- Limbah plastik poly ethylene (kemasan botol plastik $4 \mathrm{~kg}$ )

- Tanki / reaktor yang terbuat dari baja

- Termocouple ( alat ukur temperatur dalam rreaktor/tanki)

- Bomb Calorymeteri (alat ukur nilai kalor)

- Higrometer (alat ukur densitas cairan)

- Katalis Silica Alumina (1,5\% dari bahan baku plastik)

- Drum berisi air pendingin berfungsi sebagai kondenser

- Pipa Stainless untuk aliran uap p.lastik yang menuju kondenser

- Thermometer (alat ukur, untuk air kondenser)

- Botol/beaker glass ,sebagai penampung hasil (kondensad)

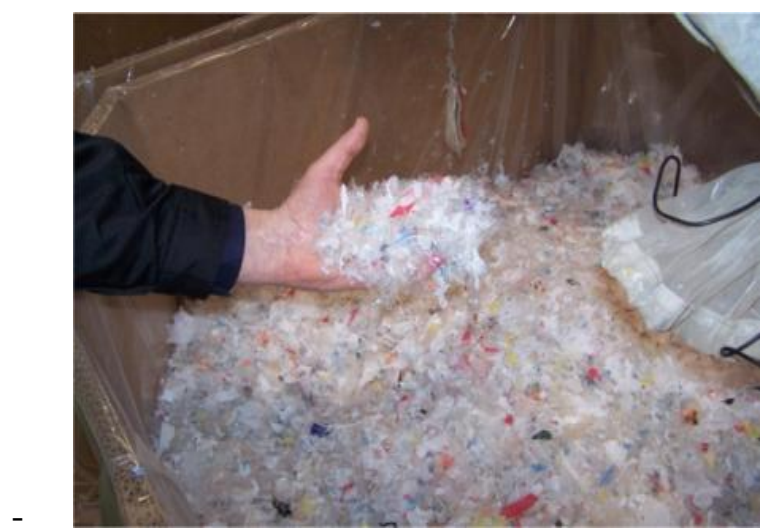

Gambar 1. bahan baku setelah dicacah

Dalam penelitian disiapkan bahan baku berupa sampah plastik khusus jenis poliethylen (HDPE) yang sudah dibersihkan dan dicacah dengan ukuran lebih kurang $1 \mathrm{~cm}$, bahan ini kemudian dimasukkan dalam Tanki baja dan ditambahkan katalis Silica Alumina sebanyak 1,5\% (60 gram ) dari bahan baku plastik yang dipakai, dengan proses pemanasan menggunakan bahan bakar LPG. Dari penelitian yang dilakukan oleh Ekki (2016), pengaruh suhu dan rato 
(Civil Engineeering, Elektrical Engineeering and Industrial Engineeering)

Vol. 16, No. 2, Oktober 2019, p-ISSN:1907-5243, e-ISSN: 2655-8416

Katalis/plastik terhadap perolehan (\% Yield) bahan bakar, diketahui bahwa yield yang dhasilkan akan meningkat seiring dengan meningkat nya suhu dan rati katalis/plastik [6]. Hal yang sama juga dikemukakan oleh Houshmand dkk (2013) , bahwa dengan meningkatnya suhu, maka semakin banyak ikatan yang terputus sehingga produk semakin banyak, yield juga semakin meningkat.

Pada variasi ratio katalis/plastik, yield yang diperoleh semakin tinggi seiring dengan meningkat nya ratio. Hal ini disebabkan semakin banyak jumlah katalis yang ditambahkan, maka akan meningkat kan laju reaksi pembentukan produk dengan jalan menurunkan energi aktifasi sesuai dengan persamaan Arhenius ( [6]

$$
\mathrm{K}=\mathrm{Ko} \mathrm{e}^{-\mathrm{Ea} / \mathrm{RT}}
$$

Dimana :

$\mathrm{K}=$ Konstanta laju reaksi

$\mathrm{Ko}=$ Faktor frekuensi

$\mathrm{Ea}=$ Energi aktifasi

$\mathrm{R}=$ Konstanta gas

$\mathrm{T}=$ temperatur

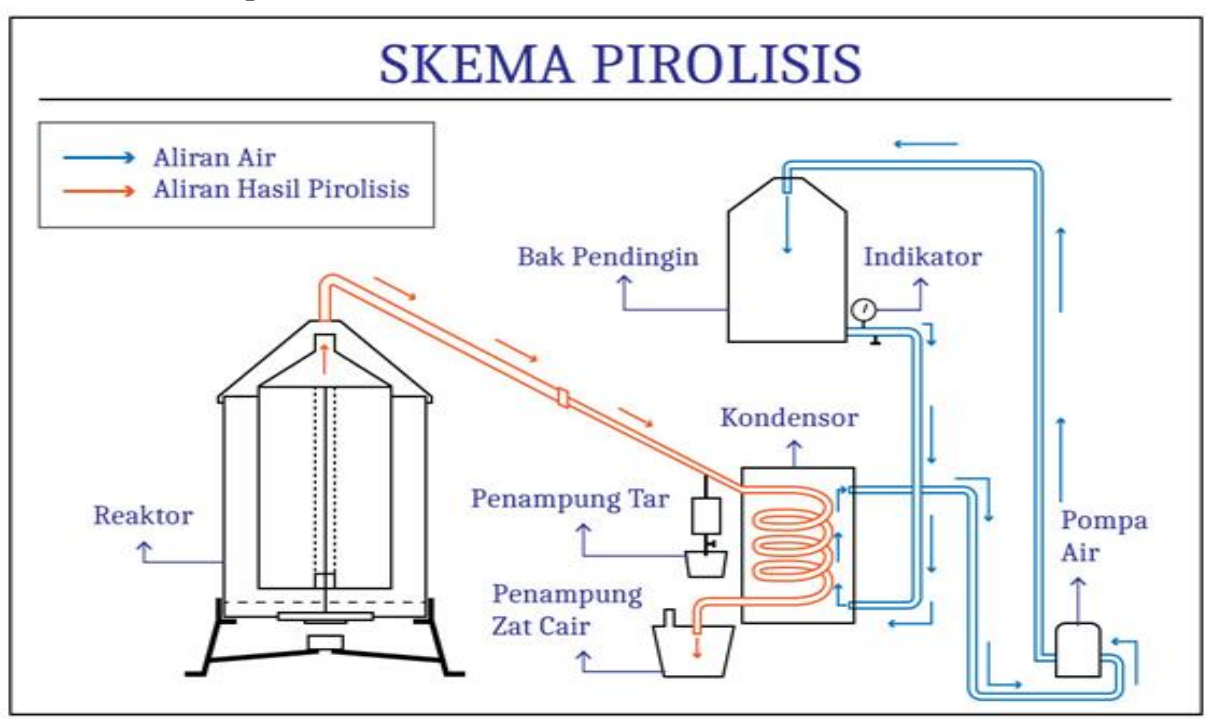

Gambar 2. Skema proses Catalitic Cracking (Pirolisis )dengan

menggunakan

katalis Silica Alumina. 
(Civil Engineeering, Elektrical Engineeering and Industrial Engineeering) Vol. 16, No. 2, Oktober 2019, p-ISSN:1907-5243, e-ISSN: 2655-8416

Produk yang berupa uap panas akan mengalir melalui pipa menuju kondensor, disini terjadi proses pendinginan dengan media air yang mengalir secara sirkulasi sehingga uap panas dari produk akan terkondensasi akibat dingin nya suhu air pendingin, sebagai akibatnya uap panas dari plastik tadi akan berubah menjadi cair, dan akan jatuh ke tempat penampungan yang sudah disediakan. Cairan yang terkondensasi ini akan berupa minyak plastik dan berwarna kuning kecoklatan. Produk yang dihasil kan berupa cairan dan gas, setelah produk cairan berhenti maka proses akan dihentikan, kemudian produk cairan, dan padatan ditimbang, dan produk gas akan diketahui massa nya setelah massa total bahan baku dikurangi dengan produk padat dan produk cairan yang ada.

Proses ini dilakukan tanpa oksigen, jadi proses ini murni terjadi akibat adanya perpindahan panas secara konduksi, konveksi dan radiasi. Temperatur dalam tangki baja bergerak merambat naik dari awal ,mulai dari $25^{\circ} \mathrm{C}$ sampai dengan $400^{\circ} \mathrm{C}$, disini terjadi proses pencairan, dan penguapan, uap yang terjadi dalam reaktor selanjud nya akan mengalir melalui pipa stainless dan kemudian masuk kedalam kondenser, disini uap tersebut akan didinginkan temperatur air kondenser $30-35^{\circ} \mathrm{C}$. Dalam penelitian ini proses berlangsung selama $3 \mathrm{jam}$, dan menghasilkan produk cair ( minyak plastik) sekitar 50-55\%, bahan padat berupa arang (Tar) berkisar $25 \%$ serta sisanya berupa gas yang merupakan selisih dari bahan baku yang dipakai dengan hasil berupa bahan bakar cair serta arang. Bahan bakar cair yang didapat berwarna kuning kecoklatan yang diperkirakan berupa senyawa kerosin.

\section{HASIL DAN PEMBAHASAN}

Dari hasil penelitian pembuatan bahan bakar cair dengan menggunakan katalis Silica Alumina dapat diketahui bahwa hasil produk yang didapat berupa bahan bakar cair lebih kurang 50-55\% \% dari bahan baku yang digunakan, sedangkan bahan produk padat berupa arang (Tar) sekitar $25 \%$ sedangkan sisanya akan berupa produk gas, yang dapat diprediksi dengan jalan mengurangi jumlah bahan baku awal dengan hasil produk (bahan bakar cair + bahan produk padat berupa arang/ Tar).

\section{Tabel 2. Hasil Poses Catalitic Cracking dengan katalis Silica Alumina}

\begin{tabular}{cccc}
\hline No. & $\begin{array}{c}\text { Waktu } \\
(\text { menit })\end{array}$ & $\begin{array}{c}\text { Temperatur } \\
\left({ }^{\circ} \mathrm{C}\right)\end{array}$ & $\begin{array}{c}\text { Volume Kondensad } \\
(\mathrm{ml})\end{array}$ \\
\hline 1. & 30 & 65 & 0
\end{tabular}




\begin{tabular}{cccc}
2. & 60 & 160 & 125 \\
3. & 90 & 200 & 159 \\
4. & 120 & 250 & 275 \\
5. & 150 & 300 & 155 \\
6. & 180 & 350 & 70 \\
7. & 210 & 400 & 25 \\
& & Total & $2154 \mathrm{ml}$ \\
\hline
\end{tabular}

sumber : Lab Teknik Industri 2019

Minyak plastik yang dihasilkan ini kemudian dilakukan pengetesan terhdap density, viskositas dan nilai kalor.

Tabel 3. Hasil Proses Catalytic Cracking

\begin{tabular}{clc}
\hline No. & Hasil Pyrolisa & \% Hasil \\
\hline 1. & Minyak & 55 \\
2. & Tar (arang) & 25 \\
3. & gas & 30 \\
\hline
\end{tabular}

Sumber : Lab Teknik Industri 2019

Hasil produk berupa bahan bakar cair berwarna kuning kecoklatan , ini kemudian di lakukan beberapa test untuk melihat sifat/karakteristik dari minyak yang didapat tersebut.

\section{Tabel 4. Sifat/Karakteristik bakar cair (Minyak)}

\begin{tabular}{lll}
\hline & $\begin{array}{l}\text { Produk Bahan bakar cair } \\
\text { (minyak) }\end{array}$ & $\begin{array}{l}\text { Sifat / Karakteristik } \\
\text { minyak }\end{array}$ \\
\hline 1. & $0,85(\mathrm{gram} / \mathrm{cc})$ & Densitas pada $30^{\circ} \mathrm{C}$ \\
2. & $41100(\mathrm{~kg} /$ joule $)$ & Nilai Kalor \\
3. & $2,095($ centipoise $)$ & Viscositas kinematis \\
4. & 53 & Cetan Number \\
5. & $40\left({ }^{\circ} \mathrm{C}\right)$ & Flash point \\
6. & $33\left({ }^{\circ} \mathrm{C}\right)$ & Pour Point \\
7. & $0,004 \% \mathrm{w}$ & Ash content \\
\hline
\end{tabular}

\section{Sumber: Lab Teknik Industri (2019)}

Nilai Kalor bahan bakar adalah suatu besaran yang menunjukkan Nilai energi kalor yang dihasilkan dari suatu proses pembakaran setiap satuan massa bahan bakar. Bahan bakar yang banyak digunakan umumnya berbentuk senyawa Hidro Carbon. Reaksi umum yang terjadi dari suatu proses pembakaran adalah 
(Civil Engineeering, Elektrical Engineeering and Industrial Engineeering)

Vol. 16, No. 2, Oktober 2019, p-ISSN:1907-5243, e-ISSN: 2655-8416

reaktan produk. Enthalpi pembakaran adalah selisih antara enthalpi dari produk dengan enthalpi dari reaktan ketika pembakaran sempurna berlangsung.Pembakaran sempurna terjadi jika komponen semua bahan bakar ( $\mathrm{C}$ dan $\mathrm{H}$ ) terbakar semua menjadi $\mathrm{CO}_{2}$ dan $\mathrm{H}_{2} \mathrm{O}$.

Berdasarkan fase $\mathrm{H}_{2} \mathrm{O}$ yang terbentuk sebagai hasil pembakaran, nilai kalor dibagi menjadi

2 jenis yaitu :

1. LHV (Lower Heating Value), yaitu nilai kalor bahan bakar, jika $\mathrm{H}_{2} \mathrm{O}$ yang dihasilkan sebagai produk pembakaran berada dalam fase uap.

2. HHV (High Heating Value) yaitu Nilai kalor bahan bakar, jika $\mathrm{H}_{2} \mathrm{O}$ yang dihasilkan sebagai produk pembakaran berada dalam fase cair.

Nilai LHV selalu lebih rendah jika dibandingkan dengan nilai HHV . Hal ini dikarenakan kalor yang dihasilkan pada proses pembakaran dengan LHV sebagian digunakan untuk mengubah $\mathrm{H}_{2} \mathrm{O}$ dari fase cair menjadi fase gas [7]. Viskositas bahan bakar adalah sifat kekentalan dari cairan yang diukur dengan menggunakan alat viscosimeter, begitu juga dengan densitas atau berat jenis adalah berat jenis dari minyak yang diukur dengan menggunakan alat Higrometer.

Flash point adalah proses kecepatan menyambar dari suatu bahan yang didapat apabila bahan bakar itu dinyalakan dengan menggunakan alat pancik atau korek api, sedang Cetane Number menunujkkan ignition quality atau kualitas pembakaran dalam ruang bakar, semakin tinggi cetane number, maka semakin bagus kualitas bahan bakar diesel tersebut.

Faktor-faktor yang mempengaruhi kualitas dan kuantitas produk minyak plastik yang dihasilkan anatara lain Temperatur dan waktu proses, jenis bahan baku plastik yang digunakan serta berbagai jenis katalis yang dipakai ,juga sangat berpengaruh. Katalis yang digunakan dalam proses catalitic cracking atau pirolisis dapat dipisahkan dan digunakan kembali sehingga dapat mengurangi biaya operasional. Selain itu emisi gas yang dihasilkan oleh proses pirolisis dengan katalis bebas dari Dioksine dan Furan yang bersifat toksik, sehingga ramah terhadap lingkungan ini menurut [8]

\section{KESIMPULAN}

Dari Hasil analisa dan pembahasan, maka dari penelitian ini dapatlah kita simpulkan hal-hal sebagai berikut : 
(Civil Engineeering, Elektrical Engineeering and Industrial Engineeering)

Vol. 16, No. 2, Oktober 2019, p-ISSN:1907-5243, e-ISSN: 2655-8416

1. Pada proses konversi sampah plastik jenis HDPE dengan metode Catalytic Cracking dan katalis Silica Alumina ,berlangsung selama 4 jam dengan suhu rendah mulai dari $100-400^{\circ} \mathrm{C}$, mengasilkan minyak plastik lebih kurang 53 $\%$.

2. Hasil test dari karakteristik minyak menunjukkan bahwa minyak yang didapat termasuk dalam kelompok kerosine samapai solar.

3. Faktor suhu dan lama proses catalitic cracking, serta jenis katalis yang dipaka juga sangat berpengaruh terhadap produk bahan bakar cair yang didapat.

\section{DAFTAR RUJUKAN}

[1] Untoro BS,2013 "Berbagai metode Konversi sampah plastic menjadi bahan bakar minyak” Jurnal Teknik vol.3 No.01 ,April 2013, ISSN 2088-3676.

[2] Bumiarto $\mathrm{Nj}$ dan $\mathrm{R}$, 2010" Aplikasi katalis dalam mengkonversi limbah plastic" Balai Besar Kimia dan Kemasan (BBKK) , Kementrian Perindustrian RI, Jakarta. ,Surakarta

[3] Budiyantoro,C.,2010, “Thermoplastik dalam Industri” ,Teknika Media

[4] Kumar dkk, 2011, A Review on Tertiary Recycling of high- density Poliethylene to fuel, Resources, Concervation and Recycling, Vol 55 893-910

[5] Sibarani, K.L (2012), Preparasi Karakterisasi dan uji aktifitas katalis Ni $\mathrm{Cr} /$ Zeolit alam pada proses perengkahan limbah plastic menjadi fraksi bensin, Skripsi Universitas Indonesia, Depok.

[6] Ekki dkk,2016 "Pengolahan sampah plastic polipropilene menjadi bahan bakar minyak dengan metode perengkahan katalitik menggunakan katalis sintetis,

[7] Sumartono,H.S2015 “ Uji karakteristik bahan bakar minyak dari Limbah Plastik" Seminar Nasional, Peran Penelitian dan Inovasi di Era Industri 4.0 Dalam mewujudkan Pembangunan berkelanjutan menuju kemandirian bangsa.

[8] Harshal, P.R dan Syailendra, L.M, 2013 Waste plastic pyrolysis oil Alternative fuel for Oil engine, Research journal of Engineering sciences. 
(Civil Engineeering, Elektrical Engineeering and Industrial Engineeering)

Vol. 16, No. 2, Oktober 2019, p-ISSN:1907-5243, e-ISSN: 2655-8416

[9] Jurnal Rekayasa Kimia dan Lingkungan Vol 11, no.1 ,hal17-23, Juni 2016 ISSN 1412-5064, e-ISSN 2356-1661.

[10] Miller S, J, Shah N and Huffman G.P. 2005." Conversion off Waste Plastic to Lubrican Base Oil " Chemical Society, 19(4), 1580-1586.

[11] Prabuditya,2016 “ Konversi limbah plastic Poliethylenen menjadi bahan bakar dengan metode pirolisis “ Jurnal Disprotek, volume 7 No.1 Januari 2016. 